\title{
Elogio de la dermatología cotidiana
}

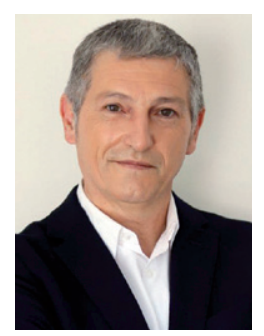

Emilio del Río de la Torre Clínica Dermalar. Santiago de Compostela (A Coruña).
A los seres humanos -incluidos los dermatólogos, por supuesto- nos fascinan dos cosas: en primer lugar, lo novedoso, lo más reciente, lo último; y casi otro tanto, lo raro, lo infrecuente y lo poco común. Así se explica que las sesiones de «Qué hay de nuevo» o de «Novedades...» se llenen una y otra vez en nuestros congresos presenciales, que jojalá vuelvan pronto! Por la misma razón, los simposios de casos excepcionales tienen tanto o más éxito, porque captan nuestra atención como una pepita de oro que brilla en el lecho del río. Ambos rasgos, a su vez, tienen mucho que ver con la necesidad que periódicamente tenemos los humanos de «romper con la rutina». Aunque, paradójicamente - y al mismo tiemponecesitemos orden, entornos conocidos, rutinas, constancia y ciclos circadianos predecibles.

La práctica dermatológica ha pasado largas décadas trabajando lo novedoso y lo infrecuente, como un explorador que avanza llamado por la poderosa atracción de territorios ignotos. Mientras que lo cotidiano, lo que «verdaderamente nos da de comer» - esto es, aquello por lo que viene a nosotros el paciente que entra por la puerta-, ha quedado relegado en la formación (y casi en nuestra escala de valores profesional) a algo obvio y previsible, ya dado por sabido y por hecho... cuando, en realidad, no lo es tanto...
En paralelo, la medicina actual tiende a abusar de expresiones grandilocuentes como «excelencia», «coste-beneficio» o «evidencia» que no ayudan mucho, contra su propio espíritu positivista, a reconectar con la dermatología esencial y de la vida real, bien por resultar rimbombantes, bien por pecar de falsa humildad. O por ser palabras desgastadas y verse relegadas a la categoría de «muletillas» o palabras vacías por exceso de uso. También en esa pretendida «búsqueda de la evidencia y de la excelencia», las guías, los protocolos, aunque necesarios y buenos, pueden ser limitantes para desarrollar nuestro sentido crítico y agudizar la curiosidad, facilitando una cierta uniformización entendida como pobreza creativa. La literatura científica, que también peca de una cierta endogamia y distanciamiento de la realidad, en la que son los mismos escribiendo de lo mismo - a menudo son actores y jueces al mismo tiempo-, tampoco facilita las aproximaciones verdaderamente novedosas y disruptivas.

Y así ha sido que el summun de la práctica dermatológica para la mayoría de nosotros, la guinda de un gran pastel profesional y el sueño de una buena carrera, parece ser desde hace décadas el ejercicio profesional en un gran servicio de dermatología de un hospital terciario, con unidades de atención diferenciadas, atendiendo linfomas cutáneos, psoriasis graves, cáncer cutáneo avanzado o procesos 
autoinmunitarios complejos con el último tratamiento biológico a nuestra disposición sin cortapisas. Afortunadamente — sobre todo, para el paciente-, esto no es así en la mayoría de los casos: el ciudadano acude a nosotros por dificultades habitualmente menos graves. Y, ocasionalmente, por motivos serios también, para los que tenemos que estar preparados. Puede que de aquí, quizás, los dermatólogos hayamos tomado como veraz la vieja idea de que «el que hace lo mucho, hace lo poco». Pero, a modo de ejemplo, si a la mayoría de nosotros nos pidiesen que hiciésemos un simple $\mathrm{KOH}$ de una toma micológica o tuviésemos que coagular sin tener un electrocauterio a mano, una buena proporción, probablemente, no sabríamos hacerlo.

La dermatología, para más abundamiento, es el paradigma de especialidad médica que mantiene en su corpus de conocimiento cientos y cientos de síndromes y enfermedades, pero la realidad es que son apenas una docena de procesos (de la dermatitis atópica al acné, pasando incluso por las verrugas vulgares) los que copan el $90 \%$ de las consultas dermatológicas del ciudadano de a pie. Por si esta invisibilización histórica de lo común fuese poco, en los últimos tiempos, la llamada hacia la «superespecialización» en alguno de los campos concretos de la dermatología como necesidad imperiosa ante el crecimiento exponencial del conocimiento parece dejar poco margen de elección a quienes queremos seguir siendo dermatólogo y venereólogo general, que, sin llegar a ser el «dermatólogo total» ni el «dermatólogo-supermán», sí que atendamos o manejemos igualmente cáncer cutáneo, psoriasis, estética o venereología como una atención primaria dermatológica vocacional. En esa reivindicación, y en la puesta en valor de la dermatología del día a día, damos un paso al frente muchos dermatólogos, particularmente, los que ejercemos a pie de calle, sin el amparo de la sanidad pública, solos — como Gary Cooper en la famosa película - ante el peligro cada día. La situación es al mismo tiempo tan simple como compleja: el paciente, que acude al médico y, en frente el dermatólogo, a quien aquel pide ayuda y este in- tenta ofrecer dos cosas, explicación y, si puede, solución. Y esta solución debe ser lo más sencilla, ágil y asequible posible. En este sentido, es clave desarrollar estrategias que reduzcan las visitas del paciente, porque, a menudo, los médicos tendemos a pensar que el tiempo del paciente nos pertenece y no nos preocupa hacerlo venir varias veces al hospital, perdiendo horas de trabajo, colegio, obligaciones familiares, etc. A modo de ejemplo, una verruga vulgar que se pueda dejar solucionada de una mínima infiltración de bleomicina en la primera - y, probablemente, única— visita es una forma de optimización que el paciente agradece. Otras enfermedades del día a día, como las queratosis actínicas, han sido siempre auténticas «cenicientas» en la práctica dermatológica hasta que fue la industria farmacéutica (un verdadero elefante en nuestra habitación), buscando pingües beneficios, la que nos ha hecho volver la vista sobre algo que ya siempre habíamos tenido ahí y no valorábamos.

La dermatología, como la vida, también tiene caminos de «ida y vuelta», aunque raramente nos devuelven exactamente al punto de partida. La cirugía, uno de los cuatro pilares de la dermatología junto con la dermatología médica, la venereología y la estética, es un buen ejemplo. Se nos ha educado para avanzar en una cirugía dermatológica del más alto nivel, en un quirófano reglado y hospitalario, para que la dermatología «no sea menos que ninguna otra especialidad quirúrgica», apoyados en personal auxiliar y anestesista... Está bien, pero... ¿y si hubiese otros caminos? ¿Y si fuese posible reducir esa intervención a lo mínimamente necesario, por ejemplo, tumorectomía simple, sin más? ¿Y si esa intervención se pudiese realizar con cirugía de mínima invasión en el quirofanillo de la consulta? Por ejemplo, extirpación por afeitado, coagulación química, desarrollando lo que podríamos llamar «cirugía de gabinete» 0 cirugía dermatológica simplificada, desprovista de todo artificio y no por ello menos resolutiva, todo lo contrario: incluso más eficiente.

En realidad, esta reivindicación de la dermatología cotidiana sin complejo ninguno no es nada 
nuevo. Los que ya tenemos unos años en esta bonita aventura de la dermatología recordamos la sección «Portrait of a practice» que el matrimonio Shelley, Walter y Dorinda, mantuvieron durante años para la revista Cutis en la pasada década de 1990. Y nos demostraban en cada número hace ya tres décadas que la dermatología del día a día puede ser una aventura fascinante, que el método clínico sigue siendo el mismo desde Sydenham, a pesar de las ayudas digitales para el diagnóstico, y que puede haber avance y margen de mejora en enfermedades tan simples como las pediculo- sis o la rosácea. Reivindicar esta «pequeña» (en el sentido más cariñoso de la palabra) dermatología cotidiana no es otra cosa que poner en valor la riqueza, vitalidad y variedad de nuestra especialidad, tener presente que la «alta dermatología» es la dermatología bien hecha, aunque con orgullosa humildad y, sobre todo, recordar cada día que no hay paciente sencillo, sino que hasta lo más simple es importante y puede tener margen de mejora. No en vano ha sido ese «pequeño problema» de piel el que ha traído al paciente hasta nosotros. 